\title{
Carbon-Based Electrode Materials for Microsupercapacitors in Self-Powering Sensor Networks: Present and Future Development
}

\author{
A. D. Smith ${ }^{1, *}$, Qi Li ${ }^{1}{ }^{1}$, Agin Vyas ${ }^{1}$ (D), Mohammad Mazharul Haque ${ }^{1}$, Kejian Wang ${ }^{1}$, \\ Andres Velasco ${ }^{1}\left(\mathbb{D}\right.$, Xiaoyan Zhang ${ }^{2}$, Shameel Thurakkal ${ }^{2}$, Arne Quellmalz ${ }^{3} \mathbb{D}$, Frank Niklaus ${ }^{3}$, \\ Kristinn Gylfason ${ }^{3}$, Per Lundgren ${ }^{1}$ (D) and Peter Enoksson ${ }^{1}$ \\ 1 Micro and Nanosystems Group, Department of Microtechnology and Nanoscience, Chalmers University of \\ Technology, 41296 Gothenburg, Sweden; qili@chalmers.se (Q.L.); agin@chalmers.se (A.V.); \\ mhaque@chalmers.se (M.M.H.); kejian@student.chalmers.se (K.W.); andres.velasco.13@gmail.com (A.V.); \\ per.lundgren@chalmers.se (P.L.); peter.enoksson@chalmers.se (P.E.) \\ 2 Chemistry on 2D Materials Group, Department of Chemistry and Chemical Engineering, Chalmers \\ University of Technology, 41296 Gothenburg, Sweden; xiaoyan.zhang@chalmers.se (X.Z.); \\ shameel@chalmers.se (S.T.) \\ 3 Department of Micro and Nanosystems, School of Electrical Engineering and Computer Science, KTH Royal \\ Institute of Technology, SE-10044 Stockholm, Sweden; arneq@kth.se (A.Q.); frank.niklaus@ee.kth.se (F.N.); \\ gylfason@kth.se (K.G.) \\ * Correspondence: smdavid@chalmers.se
}

Received: 14 August 2019; Accepted: 27 September 2019; Published: 29 September 2019

check for updates

\begin{abstract}
There is an urgent need to fulfill future energy demands for micro and nanoelectronics. This work outlines a number of important design features for carbon-based microsupercapacitors, which enhance both their performance and integration potential and are critical for complimentary metal oxide semiconductor (CMOS) compatibility. Based on these design features, we present CMOS-compatible, graphene-based microsupercapacitors that can be integrated at the back end of the line of the integrated circuit fabrication. Electrode materials and their interfaces play a crucial role for the device characteristics. As such, different carbon-based materials are discussed and the importance of careful design of current collector/electrode interfaces is emphasized. Electrode adhesion is an important factor to improve device performance and uniformity. Additionally, doping of the electrodes can greatly improve the energy density of the devices. As microsupercapacitors are engineered for targeted applications, device scaling is critically important, and we present the first steps toward general scaling trends. Last, we outline a potential future integration scheme for a complete microsystem on a chip, containing sensors, logic, power generation, power management, and power storage. Such a system would be self-powering.
\end{abstract}

Keywords: microsupercapacitors; energy storage; self-powering systems; IoT; sensor networks

\section{Introduction}

Electronic devices have been shrinking for decades in accordance with Moore's law-providing additional processing power and storage capacity with each technological iteration [1]. However, recent trends in industry, as well as physical limits of silicon technology suggest that Moore's law is nearing its end [2]. In consequence, manufacturers are searching for ever more inventive ways to continue technological progression, such as energy efficient architectures [3], three-dimensional (3D) stacking, and the addition of multiple cores, to speed up processing [2,4]. Simultaneously, as devices continue to have increased computational power, they experiencing a complimentary increase in functionality 
(diversification), which has come to be referred to as 'more-than-Moore' [2,5,6]. Diversification involves the incorporation of a wide variety of sensor components into one device-typically through a combination of system on chip ( $\mathrm{SoC}$ ) and system in package (SiP) solutions [6]. A consequence of additional functionality is an increasing power requirement. Additionally, most applications using more-than-Moore technologies, such as smart phones and wearable electronics, benefit greatly from having access to energy storage, which is quickly recharged with insignificant degradation over the device's lifetime.

Batteries have been commonly incorporated for commodity storage applications [7-9]. However, although they have high energy density, batteries suffer from poor cyclability [10] and slow recharging rates. In contrast, a relatively novel device structure, the supercapacitor, offers excellent cyclability and promises charge/discharge rates in the order of seconds [11] rather than hours-making supercapacitors an attractive alternative to batteries for future more-than-Moore applications. Supercapacitors operate primarily by employing a double-layer capacitance, meaning that ions collect along the electrode surface and attract their charge pair from the electrolyte. Consequently, materials with a high surface area can achieve a correspondingly high energy density. As such, there has been significant research investigating both wearable and flexible electronic supercapacitor applications [12-16], as well as microsupercapacitors (MSCs) for more-than-Moore applications.

One particularly attractive application involves the integration of supercapacitors with energy harvesters. Such a device combination is potentially self-powering [17-20], as excess energy from the harvester is stored in the supercapacitor for use at times of intermittent energy generation from the harvester. A combined supercapacitor and harvester component can then be connected to sensor/digital logic/memory systems and power those systems indefinitely.

Currently, supercapacitors have energy densities that are far lower than batteries. Typical commercial batteries have energy densities of $140 \mathrm{Wh} / \mathrm{kg}$ at the battery pack level [21], while commercial supercapacitors have reported energy densities that are as high as $30 \mathrm{Wh} / \mathrm{kg}$ [22]. Consequently, a substantial portion of the research into supercapacitors has been devoted to increasing their energy density. The best reported values for supercapacitors, that we are aware of, exceed $200 \mathrm{Wh} / \mathrm{kg}$ at the cell level $[23,24]$, which is comparable to the commercially available battery technology. There are a number of ways to improve supercapacitor device performance which include asymmetric electrode designs, hybrid supercapacitor/battery designs [25-29], electrolyte optimization [22,30,31], and novel electrode materials [22,30,32-38] including chemical doping of electrodes [39]. Graphene-based materials have shown a great promise as electrode materials, due to their high electrical conductivity, large surface-to-volume ratio and excellent flexibility [36,40-42]. Therefore, a number of studies have been devoted to examining graphene-based materials as electrode materials for supercapacitor applications [43-50].

The present article continues investigations into the application of graphene-based materials for supercapacitor applications, including a focused review and a report of our own design solutions to key challenges. We outline recent developments while providing an overall context of MSC design parameters and our current attempts at performance improvement. Figure 1 outlines three main areas for improvement (electrode, electrolyte, and current collector) and the two primary MSC topologies (planar, Figure 1a, and stacked, Figure 1b). We present our current progress at improving these areas and provide additional paths for future investigation. Although there are a number of electrode materials available [32], the primarily examined materials here are reduced graphene oxide (rGO) and vertically grown graphene. The contact resistances between graphene and current collectors are also critically important, as it impacts the energy losses of each charge/discharge cycle of the MSC. Hence, this work provides an analysis of graphene/current collector contact resistances under the influence of moisture, as electrodes will likely be immersed in liquid electrolyte and be subjected to moisture during their lifetime. Additionally, the implementation of chemical doping into the electrode materials is likely to improve the energy density of the supercapacitor, without any critical penalty on power density and cyclability. Consequently, this work presents the potential options for doping electrodes 
with redox-active heteroatoms. Based on the device topology, the separator can play an important role, hence, its importance is discussed. Geometric scaling of components is also examined and it represents an important incremental step in effectively engineering the desired performance of the MSC.

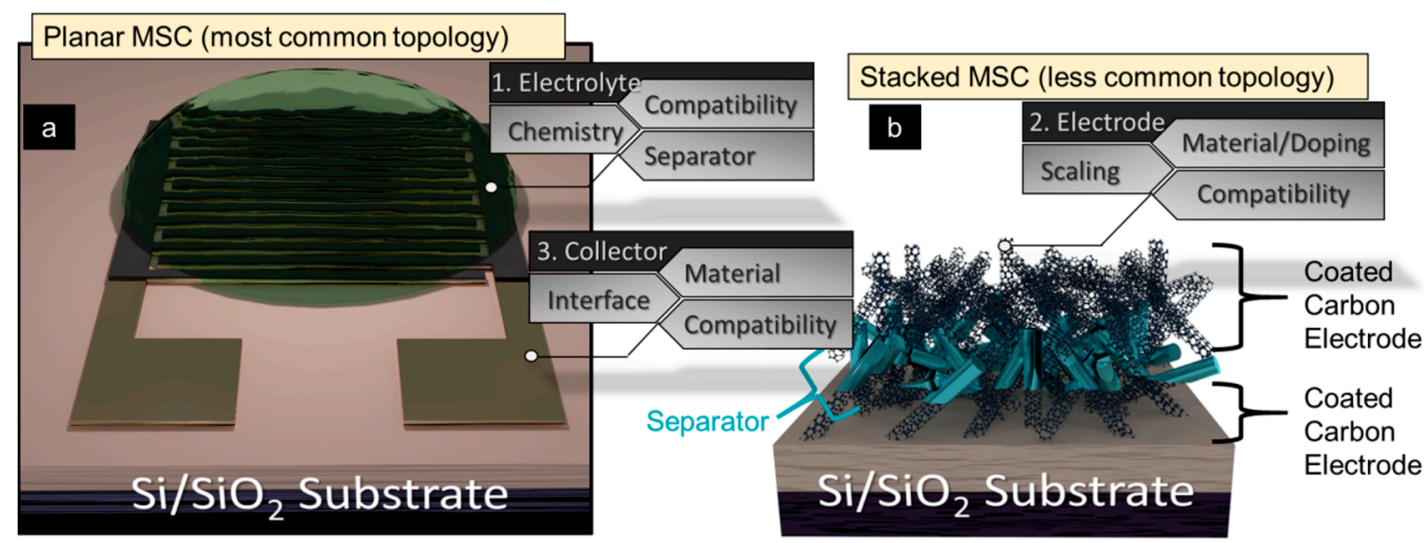

Figure 1. Schematic of a microsupercapacitors (MSCs)—planar (a) and stacked (b) —and its design parameters. There are 3 primary areas for performance improvement-electrolyte, electrode, and current collector. Each of these areas have 3 subset groups for improvement. This work aims to provide an overview of each area and subset group.

\section{Materials and Methods}

\subsection{Planar Microsupercapacitor Fabrication}

MSC s can be designed and fabricated in various ways, depending on their target application [35]. For example, flexible electronics requires foldable MSCs, which must demonstrate a stable performance under strain [51,52]. Several manufacturing approaches, such as spray coating [53,54], electrophoretic deposition [55,56], and laser patterning of thin-film electrodes [57-59], have been used to coat electrode materials onto a wide variety of target substrates (standard CMOS substrates such as $\mathrm{SiO}_{2}$ or flexible substrates such as polydimethylsiloxane (PDMS). The integration of supercapacitors with CMOS technology, requires coating and patterning methods compatible with CMOS circuits, including temperatures below $450{ }^{\circ} \mathrm{C}$. In this work, we primarily focused on MSC fabrication using a planar design (although we briefly elaborated on stacked configurations in a later section) and a fully CMOS-compatible process (Figure 2a). The process begins with a $\mathrm{Si} / \mathrm{SiO}_{2}$ wafer (Figure 2a(i)) which could in principle also be a wafer with prefabricated CMOS circuits. Current collectors are patterned on it, either through a bi-layer metal lift-off process or through a metal-etching post-blanketwafer-evaporation (Figure 2a(ii)). Some current collector materials, such as $\mathrm{Au}$ or Pd, require a diffusion barrier layer between them and an insulating substrate, as some metals tend to migrate into the pin-holes in the insulating passivation layers-short circuiting the device.

Electrodes can either be deposited or grown on the substrate, depending on the choice of the material. Techniques such as doctor-blade coating and spin-coating are effective in covering the entire wafer surface for materials such as carbon nanotubes (CNTs), reduced graphene oxides (rGOs), carbon nanofibers (CNFs), and activated carbons (ACs). Growth of CNTs, CNFs, and vertical graphene (VG) is also possible on the wafer (Figure 2a(iii)). Each method has its own advantages and disadvantages. For example, spin-coating is challenging, both for achieving a strong adhesion of the electrode to the substrate and to obtain a uniform coating. Likewise, direct growth on pre-patterned substrates is typically challenging, due to the uneven temperature distribution across the surface. In this work, we focus on spin-coated rGO and direct growth of VG. After the electrode deposition, a metal, such as $\mathrm{Al}$, is evaporated onto the electrode to act as a hard mask (Figure 2a(iv)). The exposed areas of the electrode are then etched using an $\mathrm{O}_{2}$-reactive ion-etching (Figure $2 \mathrm{a}(\mathrm{v})$ ), followed by a removal of the hard mask (Figure 2a(vi)). Lastly, an electrolyte is drop-cast onto the surface of the MSC. 


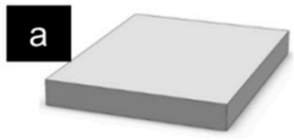

(i)

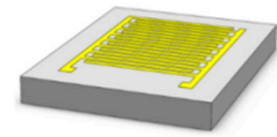

(ii)

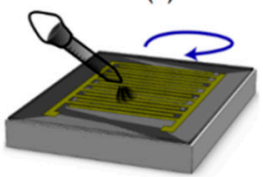

(iii)

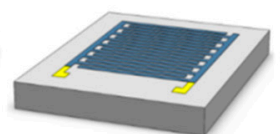

(iv)

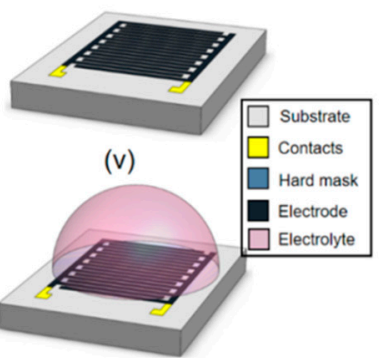

(vi)
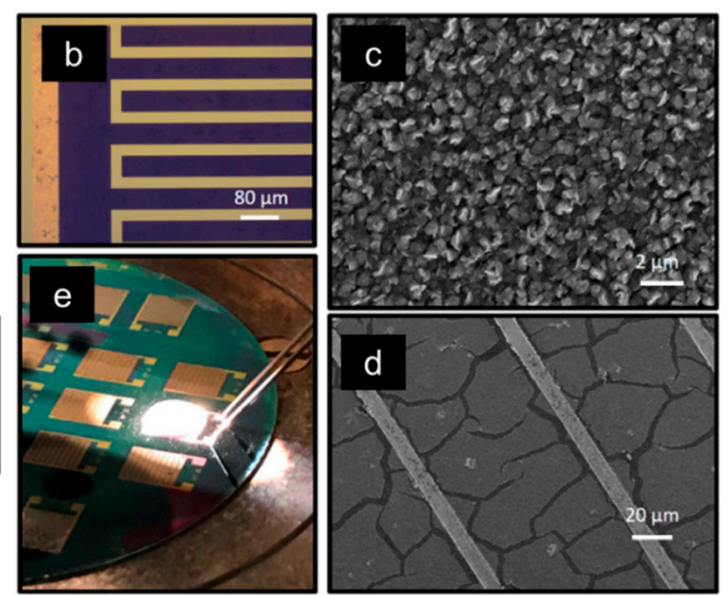

Figure 2. (a) Schematic CMOS compatible process for MSC fabrication. (b) Optical micrograph of the fabricated intedigitated reduced graphene oxide ( $\mathrm{rGO}$ ) electrodes on $\mathrm{Au} / \mathrm{Ti}$ current collectors. (c) Graphical SEM image of vertical graphene on a $50 \mathrm{~mm}$ diameter $\mathrm{Si} / \mathrm{SiO}_{2}$ wafer with $\mathrm{Au} / \mathrm{Ti}$ collectors.

(d) SEM image of rGO on Fe/Ti/Au current collectors. (e) Electrochemical test setup of fabricated rGO-MSCs with $\mathrm{H}_{3} \mathrm{PO}_{4}$ /polyvinyl alcohol (PVA) electrolyte.

\subsection{Electrode Materials}

As previously mentioned, to be compatible with the top-down approach for microsupercapacitor manufacturing, the active electrode, collector, and separator materials must be deposited onto the surface of wafers. The deposition of the electrode material can be achieved through two different strategies, i.e., spin-coating and a direct growth of materials $[17,36,44]$. For the spin coating route, stable inks containing supercapacitor active materials must be prepared. To this end, we have successfully demonstrated graphene oxide (GO) and carbon nanotubes (CNTs). For the direct growth, we have uniformly grown vertical graphene (VG) on wafer surfaces. Representative SEM images of the respective investigated electrode approaches are shown in Figure 3.
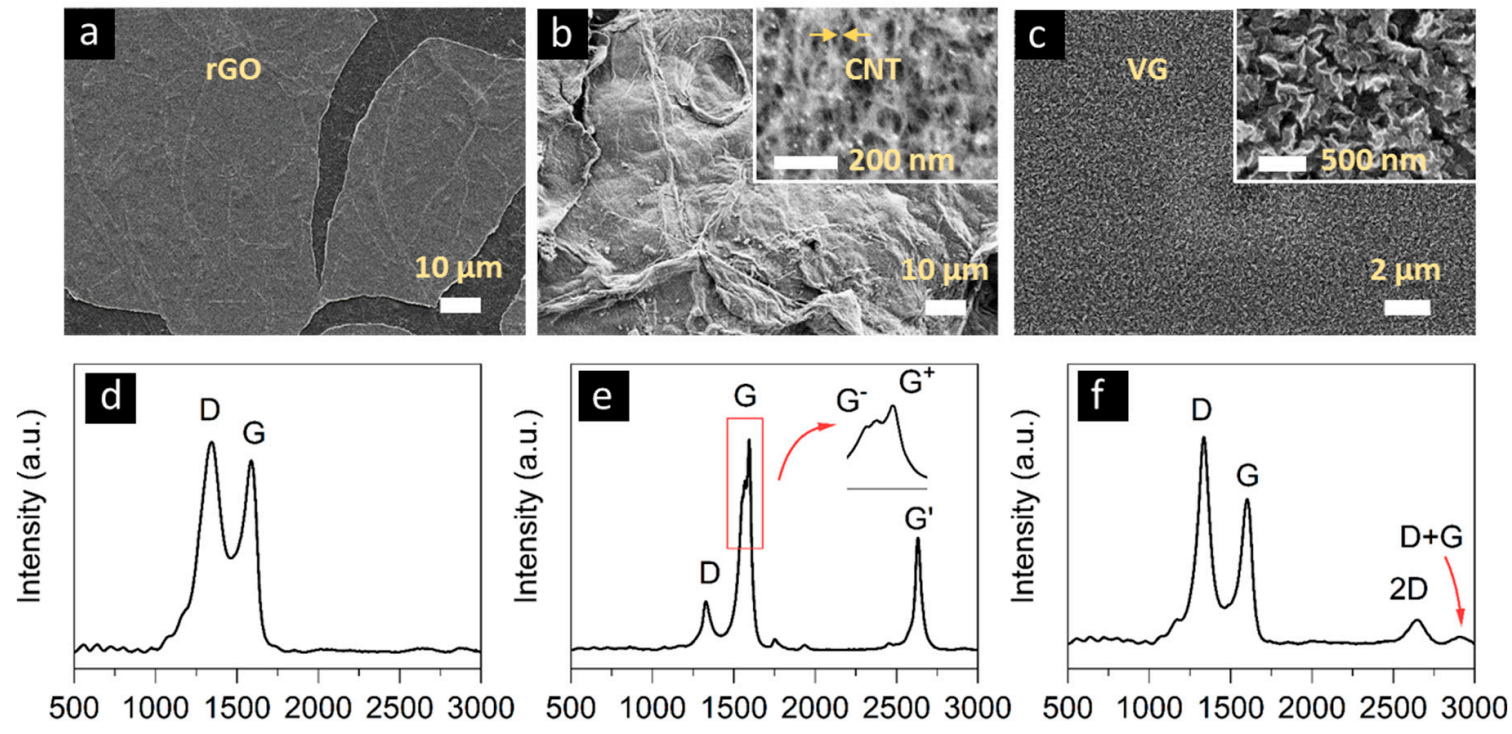

Raman shift $\left(\mathrm{cm}^{-1}\right)$

Raman shift $\left(\mathrm{cm}^{-1}\right)$

Raman shift $\left(\mathrm{cm}^{-1}\right)$

Figure 3. SEM images of (a) rGO, (b) carbon nanotubes (CNT), and (c) a vertical graphene (VG) layer as electrode materials on an $\mathrm{SiO}_{2}$ surface. Insets show higher magnification of the respective sample. Raman spectroscopy images of each material are shown in (d), (e), and (f), respectively. 
Additionally, Raman spectra of rGO, CNT, and VG are shown in Figure 3d, e, and f, respectively. Two fundamental vibrations can be found for $\mathrm{rGO}$, as shown in Figure $3 \mathrm{~d}$. The $\mathrm{D}$ band originated from a breathing mode of j-point photons of A1g symmetry, and the $\mathrm{G}$ band is from first-order scattering of E2g phonons by sp ${ }^{2}$ carbon [60], as well as $C-C$ stretching [61]. The intensity ratio of $G$ to $D$ bands $\left(\mathrm{I}_{\mathrm{G}} / \mathrm{I}_{\mathrm{D}}\right)$ is correlated with the amount of defects in graphitic materials [62]. The ratio is calculated to be 1.10 for rGO and is comparable to other reported rGO materials [63]. Raman spectrum of CNTs is shown in Figure 3e. D, G, and $G^{\prime}$ bands can be recognized at about 1327, 1594, $2631 \mathrm{~cm}^{-1}$, respectively. Noticeably, the G band is split into G+ and G- bands, attributed to a slight carbon sheet curvature and is considered to be a signature of CNTs [48]. The ID/IG ratios is 0.23 , indicating a relatively low defect concentration for the CNTs. Figure $3 \mathrm{f}$ displays typical features of VG-besides the D and G bands, a secondary D (2D) band is observed at about $2648 \mathrm{~cm}^{-1}$, and a G + D band [64] at around $2913 \mathrm{~cm}^{-1}$. The ID/IG ratio is about 1.43 for the VG used in this work, comparable to previous reports [65].

\subsubsection{Graphene Oxide (GO)}

Highly concentrated single layer GO solution was purchased from Graphene Supermarket. The commercial GO solution is prepared through a modified Hummers method by reacting graphite with a mixture of potassium permanganate $\left(\mathrm{KMnO}_{4}\right)$, concentrated sulfuric acid $\left(\mathrm{H}_{2} \mathrm{SO}_{4}\right)$, and sodium nitrate $\left(\mathrm{NaNO}_{3}\right)$. The oxygen-containing surface functional groups have a high affinity to water molecules, therefore, GO is hydrophilic and 'dispersible' in water. The flake size of GO ranges from 0.5 to $5 \mu \mathrm{m}$, with a single layer GO content of over $80 \%$. The purchased water-based ink has a concentration of $6.2 \mathrm{~g} / \mathrm{L}$ and was later diluted to $3 \mathrm{~g} / \mathrm{L}$, by adding deionized water.

Due to the insulating nature of GO caused by the disrupted $\mathrm{sp}^{2}$ bonding network, a reduction step is required to recover most of the properties of graphene. GO reduction can be done through chemical, thermal, or electrochemical means. In the present study, the GO was thermally or chemically reduced. Besides reduction of oxygen-containing groups, exfoliation of stacked GO occurs at a high temperature, due to gas (e.g., $\mathrm{CO}_{2}$ ) production-improving the surface area [66].

\subsubsection{Carbon Nanotubes (CNTs)}

CNTs have a narrow distribution of size (diameter) in the nanometer range, a highly accessible surface area, high conductivity, and stability. These features are promising for supercapacitor applications. However, CNTs tend to form large agglomerates, making the processing and stabilization of CNT-containing inks for spin-coating challenging. To counter this problem, external energy needs to be supplied to overcome the internal forces holding the aggregates together. Moreover, after the CNTs detach from the aggregates, there is a possibility of re-agglomeration. Therefore, a suitable type of surfactant is needed to stabilize them in water-based solutions.

In the present study, the CNT dispersions were prepared according to a previous work [67]. In general, $30 \mathrm{mg}$ of CNTs was dispersed in $15 \mathrm{~mL}$ of water. The dispersion was prepared by first stirring the CNTs with a $7 \mathrm{~mL}$ water at $90^{\circ} \mathrm{C}$ in a water bath, for $1 \mathrm{~h}$, followed by 20 min sonication to increase the energy for de-agglomeration. Afterwards, cetyltrimethylammonium bromide (CTAB), which was used as a surfactant to prepare a stable dispersion, was added in an $8 \mathrm{~mL}$ solution form. By keeping the mixture at $90^{\circ} \mathrm{C}$ for another $1 \mathrm{~h}$ under constant stirring and $20 \mathrm{~min}$ of sonication, the dispersion was centrifuged to remove the undispersed CNTs.

\subsubsection{Vertical Graphene (VG)}

Horizontal graphene has poor out-of-plane conductivity and a limited accessible area for capacitive energy storage, thereby, limiting its performance in microsupercapacitors. In contrast, vertical graphene has a high out-of-plane electrical conductivity, large surface-to-volume ratio, and an open network structure with graphene-like flakes oriented perpendicularly to the substrate. The vertical arrangement was beneficial for capacitive energy storage, due to a high-ion diffusivity and ion accessibility. 
In this work, we implemented a plasma-enhanced chemical vapor deposition (PECVD) process to grow VG. Hydrogen, argon, and acetylene gases were used as a reducing agent, carrier gas, and carbon source, respectively, for the growth. The wafer substrate was heated up to $775^{\circ} \mathrm{C}$ under argon and hydrogen, and then acetylene was introduced to grow the VG for $10 \mathrm{~min}$ under an $80 \mathrm{~W}$ direct current plasma.

\section{Results}

\subsection{Electrode Adhesion}

Spin-coated electrode materials can suffer from issues related to poor adhesion to the wafer substrate and current collectors. These issues are two-fold. First, the material deposited through spin-coating is non-uniform. The thickness of the fabricated electrodes varies substantially. This leads to an uneven device performance across devices on the wafer. Second, the fabrication of MSCs involves submersion of the wafer into various developers. If the electrodes do not adequately adhere to the surface, the process leads to a loss of electrode material. This eventually leads to a poor device manufacturing yield. There are two main causes for these issues. The substrates are typically Si wafers covered with an insulating thermally grown thin-film of $\mathrm{SiO}_{2}$. On top of this, metal current collectors are deposited and patterned. The current collector and $\mathrm{SiO}_{2}$ surfaces typically do not have the surface roughness necessary to ensure a reliable adhesion of the electrode flakes onto the surfaces.

Use of hydrophilic nanoparticles provides higher surface roughness on the substrate. Studies have demonstrated that the use of Fe-nanoparticles fabricated by evaporation and annealing of a $4 \mathrm{~nm}$ Fe layer at $600{ }^{\circ} \mathrm{C}$ affects the adhesion and uniformity of the spin-coated electrodes [10]. Figure $4 \mathrm{a}$ shows the atomic force microscopy (AFM) profiles of the Fe and bare $\mathrm{SiO}_{2}$ surfaces on $1 \mathrm{~cm}^{2}$ chips and the optical micrograph of the subsequent spin-coated wafer. The Fe surface demonstrates an average roughness of $2.1 \mathrm{~nm}$, while the $\mathrm{SiO}_{2}$ surface has a roughness of only $0.28 \mathrm{~nm}$. The surface on the roughened wafer is completely covered with a pink hue, while the non-roughened wafer is covered only in some areas. Figure $4 \mathrm{~b}$ shows the percentage coverage of the spin-coated electrodes on different surfaces (percentages calculated based on optical microscopy of the surfaces). The surface with nanoparticles demonstrates the highest coverage, whereas the $\mathrm{SiO}_{2}$ (control) substrate has the lowest coverage on the entire wafer. The experiments performed include the spin-coating on an un-roughened surface (control group in red), a roughened surface without current collectors (blue), a roughened surface with Ti/Au current collectors (yellow), and 3 roughened surfaces with Ar plasma bombardment as a post-treatment to attempt to further enhance roughening. Ar post-treatments were attempted at durations of 3,6 , and 10 minutes (teal, grey-blue, and purple, respectively). The experiments pertaining to coverage demonstrate that the use of Ar ions to further roughen the surface proves counter intuitive, as they reduce the surface roughness and, thereby, the percentage coverage of the spin-coated electrode material on the entire wafer. Furthermore, increased roughness leads to a larger capacitance of the MSCs. Figure $4 \mathrm{c}$ shows the cyclic voltammograms of the roughened and non-roughened $\left(\mathrm{Si} / \mathrm{SiO}_{2} / \mathrm{Ti}-\mathrm{Au}\right.$ surfaces) MSCs and clearly indicates a larger charge storage for the roughened devices. The capacitance for the MSCs was calculated from the cyclic voltammetry measurements using $C=\frac{Q}{(2 * \Delta V)}$ where $Q$ is the total charge accumulated over a $\Delta V$ voltage potential. The factor of 2 in the denominator comes from the average of the charging and the discharging area of the current curves. The areal capacitance $\left(C_{A}\right)$ of an individual device was calculated by $C_{A}=C / A$, where $A$ is the area of the MSC. Most of the devices fabricated on the roughened surfaces demonstrate a 1.5x improvement in the areal capacitance across all scan rates, from $0.1 \mathrm{~V} \mathrm{~s}^{-1}$ to $5 \mathrm{~V} \mathrm{~s}^{-1}$. A large capacitance directly translates into a higher energy and power densities for the roughened MSCs, as shown in Figure $4 \mathrm{~d}$. The energy density is calculated from $E=\frac{1}{2} C_{A} \Delta V^{2}$ and the power density is acquired from $P=\frac{E}{t}$, where $t$ is the discharge time. Thus, enhancing the surface roughness through nanoparticle deposition can improve the performance of MSCs (regardless of device topology), make the fabrication steps more stable, and lead to a greater device yield with a uniform controllable performance. 

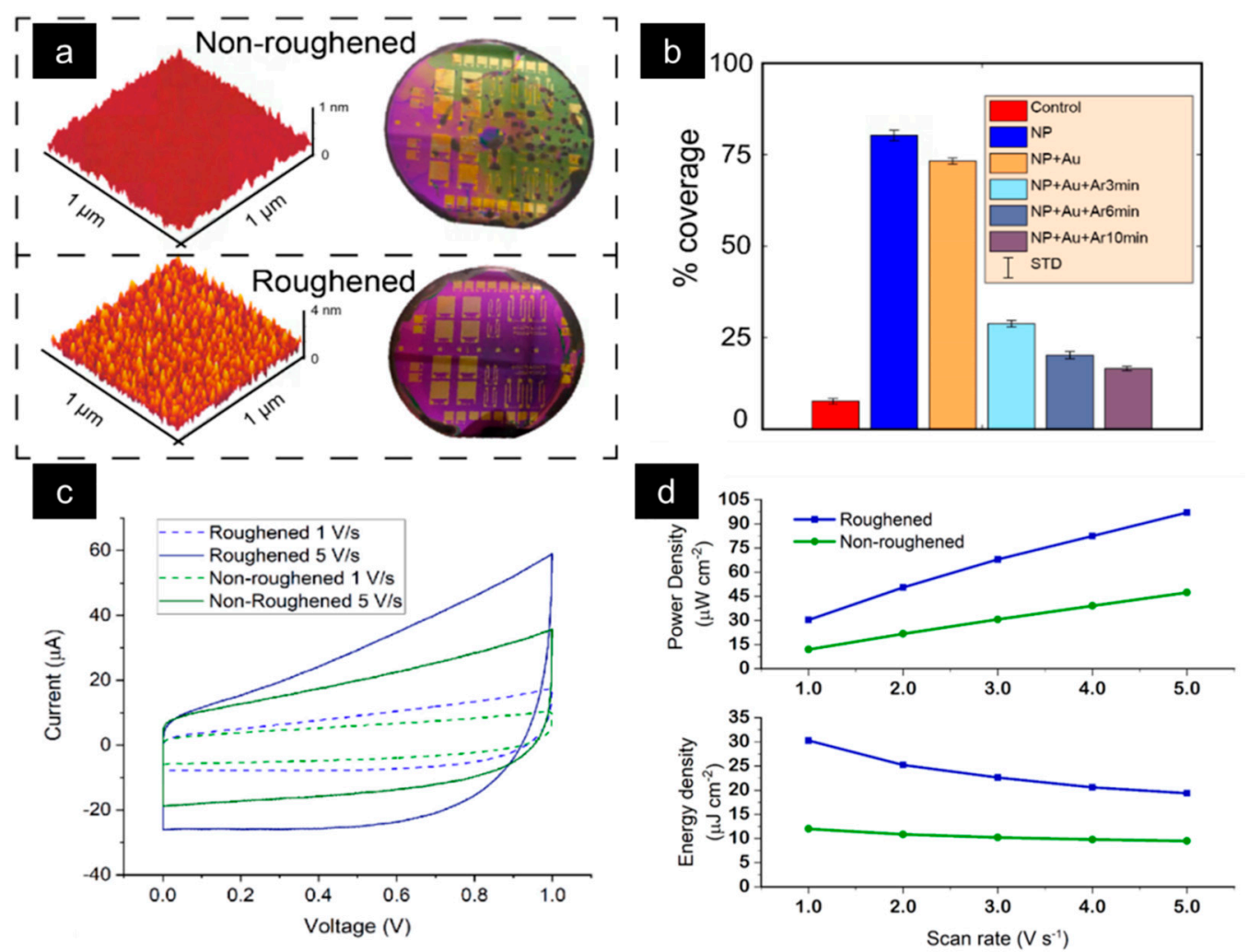

Figure 4. (a) AFM comparison of roughened and non-roughened sample surfaces along with optical microscopy images showing the coverage of the electrode spin-coating. (b) rGO spin-coated chips under different design variations (percentages of surface coverage evaluated from the optical microscopy images). Note that all roughened samples outperform the non-roughened. (c) Cyclic voltammograms, and (d) energy and power densities of the fabricated roughened and non-roughened MSCs with 1-Ethyl-3-methylimidazolium Bis(trifluoromethanesulfonyl)imide (EMIM-TFSI) electrolyte.

\subsection{Electrode Doping for Performance Enhancement}

Chemical doping of carbon-based nanomaterials with heteroatoms $(\mathrm{B}, \mathrm{N}, \mathrm{O}, \mathrm{S}, \mathrm{P})$ has attracted tremendous attention due to their improved physicochemical properties and better energy density performance compared with undoped samples [68]. Among them, nitrogen-doped, carbon-based nanomaterials have shown superior electrochemical performances as electrode materials in supercapacitors. In general, nitrogen doping leads to the formation of different nitrogen sites, such as pyrrolic $\mathrm{N}$, pyridinic $\mathrm{N}$, and quaternary $\mathrm{N} /$ graphitic $\mathrm{N}$ [69]. This improves the active surface area and thereby the wettability by introducing extrinsic defects in the carbon networks; contributes to the surface faradaic reactions; and finally leads to an enhanced electrochemical performance. Chemical treatment of graphene, for example, GO with reactive nitrogen sources such as urea, melamine, polyaniline, or ammonia is an effective way to obtain nitrogen-doped rGO. As shown in Figure 5a, we have prepared nitrogen-doped rGO through a hydrothermal process, by reacting GO with ammonia solution at $180^{\circ} \mathrm{C}$, overnight. The content of nitrogen in the N-doped rGO could be up to $5.8 \%$. As a control, GO was also reduced to rGO using the same reaction condition, without the addition of ammonia solution. Then, both rGO and nitrogen-doped rGO were employed as electrode materials in a two-electrode configuration for supercapacitor measurements. Figure $5 \mathrm{~b}$ shows the galvanostatic charge-discharge (GCD) plot of rGO and nitrogen-doped $\mathrm{rGO}$, at a current density of $0.5 \mathrm{~A} \mathrm{~g}^{-1}$. The specific capacitance was calculated to be $98,176 \mathrm{~F} \mathrm{~g}^{-1}$ for $\mathrm{rGO}$, and $\mathrm{N}$-doped rGO, respectively. Compared with rGO, N-doped rGO showed an improved electrochemical performance due to the introduction of nitrogen doping. 
a
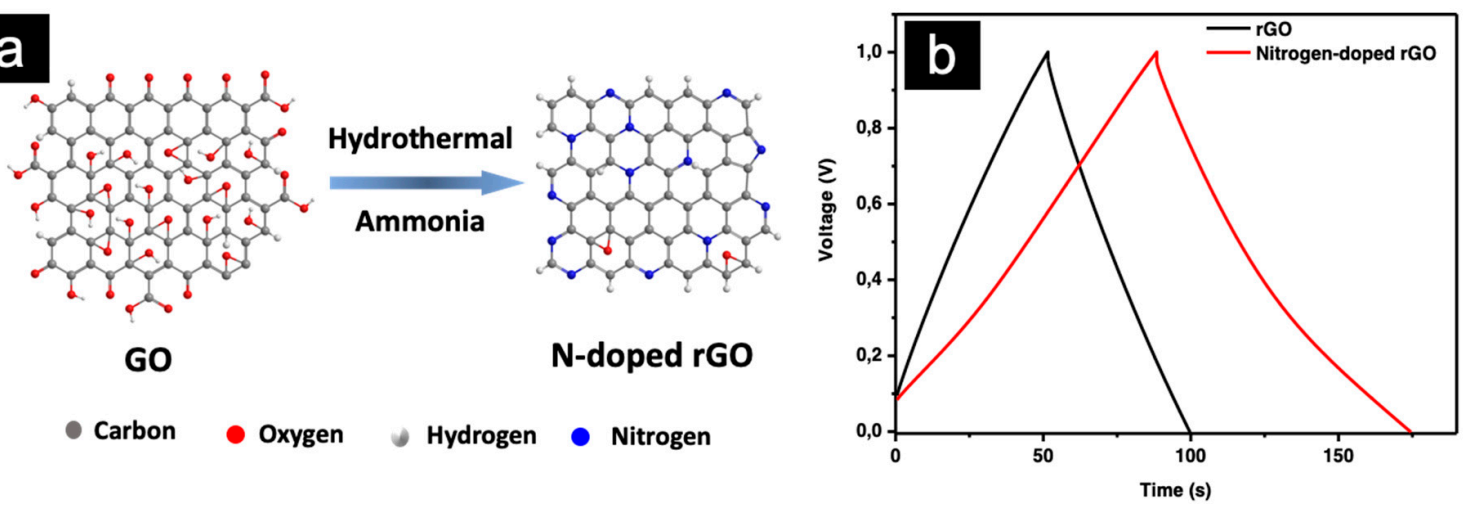

Figure 5. (a) Preparation of nitrogen-doped rGO from graphene oxide (GO) and ammonia solution (as the nitrogen precursor) through a hydrothermal process; (b) a galvanostatic charge-discharge (GCD) plot of rGO and a nitrogen-doped rGO.

\subsection{Geometric Scaling of Electrodes}

The capacitance of an MSC is critically dependent on the total electrode surface area. Consequently, the pore structure of the respective carbon-based material is important, as well as the geometric structure of the collectors and the electrodes. In order to accurately engineer a device with the desired capacitive behavior, we must also understand this scaling. Therefore, we have undertaken an extensive exploration of device scaling principles for both the areal geometry of the collectors and the electrodes, as well as the electrode height differences. This provides a good foundation for extrapolating how performance would be improved through modification of the collector and electrode geometry. Figure 6a displays the geometries investigated.

a Examples of Design Variations

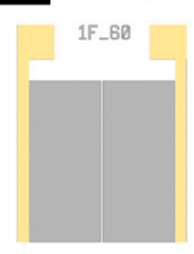

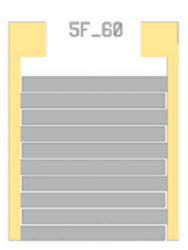

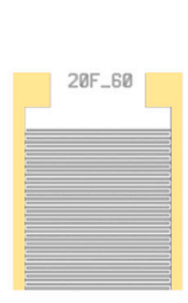

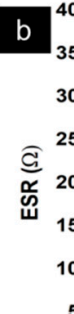

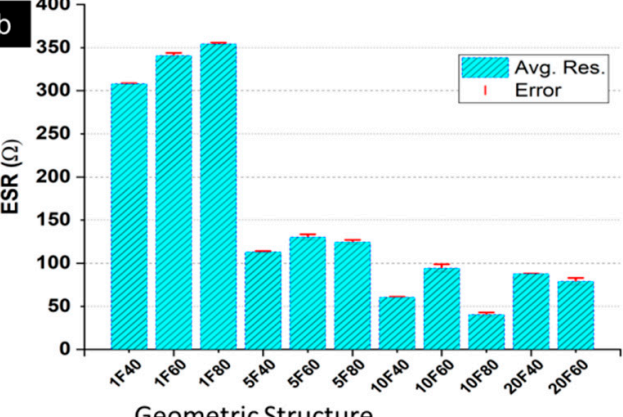

Geometric Structure

d Total Capacitance with Different CNT heights

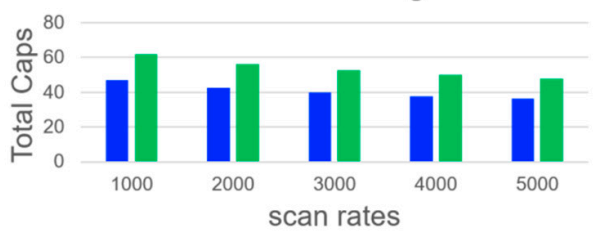

- Sample A 10F40 |- Sample B 10F40

Figure 6. (a) 2D structural variations of the collectors and carbon-based electrodes of the MSCs where $1 \mathrm{~F}, 5 \mathrm{~F}$, etc. denotes the number of fingered pairs of the collectors and electrodes and ' 60 ' represents the spacing (in $\mu \mathrm{m}$ ) between the fingers. (b) Measured average equivalent series resistance (ESR) for different collectors and electrode geometries representing 19 devices and 57 measurements. (c) Specific capacitance normalized for electrode height for two samples of different heights (3-4 $\mu \mathrm{m}$ for sample A and 5-6 $\mu \mathrm{m}$ for sample B). (d) Total capacitance for the two samples of different electrode heights (3-4 $\mu \mathrm{m}$ for sample A and 5-6 $\mu \mathrm{m}$ in B). 
Figure $6 \mathrm{~b}$ represents the measured average equivalent series resistance (ESR) for different geometric structures-suggesting that the collector and electrode geometry affects the power density. A total of 57 measurements were performed on 19 devices. Figure $6 \mathrm{c}$ and $\mathrm{d}$ are capacitance comparisons for the two samples with different electrode heights. Sample B is a thicker deposited electrode layer than Sample A (3-4 $\mu \mathrm{m}$ for sample A and 5-6 $\mu \mathrm{m}$ for sample B) and, thus, has a higher total capacitance. Significantly, when normalized for the height (Figure $6 \mathrm{c}$ ), the specific capacitance is relatively constant-meaning that there is good penetration of the ions into the electrode and that the height scaled very well with the predicted trends (Figure 6d). In summary, we find that both energy and power density are affected by device geometry. This scalability of device properties is important for the design of future integrated MSC systems, which must follow spatial design constraints while fulfilling performance specifications. Without investigation into scaling, such device engineering would be unreliable. Here, we present the first steps toward understanding those scaling principles.

\subsection{Separator Considerations for Stacked MSC Configurations}

The electrode materials and electrolytes are the most influential constituents of a high performance MSC device. As a consequence, significant research has been focused on improving the capacitive performance by exploring different kind of electrode and electrolyte materials and designs [31,44,70]. Further, for planar MSCs, the investigation of separators is unnecessary (as the separator is special), while for stacked MSC configurations the separator is more important. Although planar MSCs are the primary focus of this article, some discussion of separators and ways to improve them is merited for providing a more complete overview of performance improving device metrics for both planar and stacked configurations.

A separator, an electrically insulating but ionically conducting membrane, is placed between two electrode materials of a device, in order to prevent electrode short circuit, while allowing an electrolyte ion diffusion with minimal obstruction. Therefore, the separator holds a critical role to suppress the failure of the MSC and to ensure a safe operation, which is especially important for applications such as medical devices. In addition, the separator could also make a significant difference for the MSC device performance by means of certain characteristic properties, such as thickness, porosity, wettability, chemical, and thermal stability. Ideally, a separator should hold certain properties as listed below [71]:

- Thickness: It should be as thin as possible without compromising mechanical stability or electrical reliability.

- Chemical stability: It should not react with the electrodes or the electrolyte under any circumstances. Otherwise, separator membrane degradation will compromise the reliability of the MSC device.

- Porosity: Porosity determines the amount of electrolyte the separator can hold in its pores to facilitate better ionic conductivity. At the same time, a highly porous separator might degrade under the influence of electrolytes. The standard porosity of typical separators is about $40 \%$.

- Pore Size: Pore size should be in accordance with the pore size of the electrodes. For better performance, the ion size of the electrolytes should also be taken into account. In practice, separator membranes with sub-micron pore size are sufficient.

- Wettability: The separator should be easily wetted by aqueous electrolyte (hydrophilic) or non-aqueous electrolyte (hydrophobic) and should reliably hold the electrolyte for a very long time.

- Permeability: The presence of the separator should not influence the characteristics of the electrolyte. The loss of ionic conductivity can be expressed with a parameter called the Macmulin number. This is calculated as the ratio between the resistance of electrolyte in presence of a separator and the resistance of a pristine electrolyte. The Macmulin number of practical separators is of the order 10-12. Homogeneous composition of the separator material is also important to achieve an improved permeability. 
We carried out a comparative electrochemical study of supercapacitors containing activated carbon (AC) electrodes, 1-ethyl-3-methylimidazolium acetate (EmImAc) ionic liquid electrolyte, and three different separators-(1) an electrospun polyvinylpyrrolidone (PVP) membrane with a thickness of $90 \mu \mathrm{m}$; (2) a commercially available glass fiber (GF) with a thickness of $200 \mu \mathrm{m}$; and (3) a Celgard membrane with a thickness of $25 \mu \mathrm{m}$. The AC electrode materials were synthesized according to the procedure mentioned in [72]. The supercapacitor test device was prepared with a two-electrode Swagelok cell containing a SS316 current collector. Three different electrochemical measurements were conducted-(1) GCD, (2) electrochemical impedance spectroscopy (EIS), and (3) open circuit voltage $(\mathrm{OCV})$ decay. All electrochemical measurements were conducted at room temperature with a Gamry Reference 3000AE potentiostat/galvanostat.

Figure 7a illustrates the GCD plots of the supercapacitors at a current density of $0.5 \mathrm{~A} \mathrm{~g}^{-1}$. All curves followed a triangular shape representative of a typical capacitive behavior. Longer charging and discharging times for the PVP-containing supercapacitor demonstrated a superior performance as compared to the commercial separators. As a consequence, the specific capacitance at $0.5 \mathrm{~A} \mathrm{~g}^{-1}$ was calculated to be $99 \mathrm{~F} \mathrm{~g}^{-1}$ for the PVP-containing MSC while it was 82 and $52 \mathrm{~F} \mathrm{~g}^{-1}$ for the MSCs-containing GF and Celgard, respectively. The specific capacitance was calculated according to the equations mentioned in [72]. Figure $7 \mathrm{~b}$ shows the variation of the specific capacitance over time for the three different separators. Accordingly, a rate capability (capacitance at $10 \mathrm{~A} \mathrm{~g}^{-1}$ relative to $0.5 \mathrm{~A} \mathrm{~g}^{-1}$ ) was calculated to be $60 \%$ for the PVP, compared to $62 \%$ and $49 \%$ for the GF and Celgard-containing MSCs, respectively. Figure 7c-e display the SEM images of the PVP, Glass fiber, and Celgard separators, respectively.
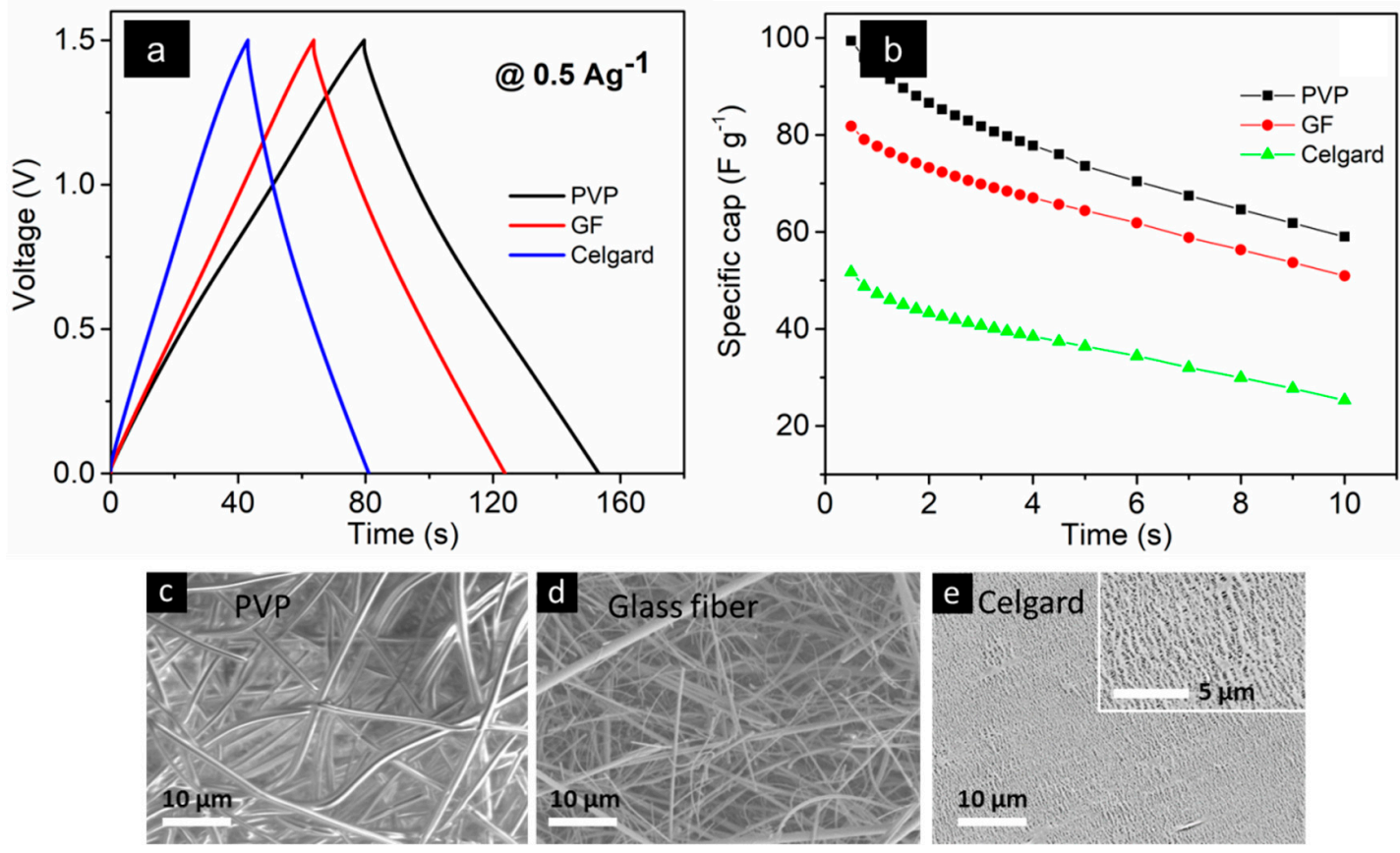

Figure 7. Measurements of supercapacitor devices including (a) GCD plots and (b) capacitance variations at different current densities. The measurements were done on an MSC with an AC electrode, a 1-ethyl-3-methylimidazolium acetate (EmImAc) ionic liquid electrolyte, and three different separators. (c-e) SEM images of polyvinylpyrrolidone (PVP), Glass fiber, and Celgard separators, respectively.

Figure 8 shows an electrochemical impedance spectroscopy graph (Nyquist plot), which was used to extract the equivalent series resistance (ESR) values of the devices (first intersection of the semi-circle in the $X$-axis represents the ESR). The ESR of the PVP-containing supercapacitor is smaller $\left(0.7 \Omega \mathrm{cm}^{2}\right)$, as compared to the GF- and Celgard-containing supercapacitors, 2.2 and $3.6 \Omega \mathrm{cm}^{2}$, respectively. This was due to the good wettability and excellent porosity of the electrospun PVP separator membrane. 
The wettability of the separators were observed during electrolyte injection to be in the decreasing order for PVP, GF, and Celgard, respectively. Figure 8b shows the OCV decay (self-discharge) behavior of the MSCs. The voltage retention at the end of a one-hour interval was calculated to be $70 \%$ for the PVP-containing supercapacitor and $61 \%$ and $36 \%$ for the supercapacitors-containing GF and Celgard, respectively. In order to observe the wettability, a tentative contact angle measurement was carried out by injecting the EMIM Ac electrolyte in all three different separators. Figure 8c-e show the contact angle of the Celgard, Glass fiber, and PVP separators, respectively. For Celgard, the contact angle was measured to be $68^{\circ}$ after 30 seconds of pouring the electrolyte droplet. The contact angles for Glass fiber and PVP separators were $46^{\circ}$ and $45^{\circ}$, respectively, after just 3 seconds of pouring the electrolyte droplet and most of the electrolytes were absorbed by the end of 10 secs. Therefore, both the Glass fiber and PVP separators have superior wettability than the Celgard separator.
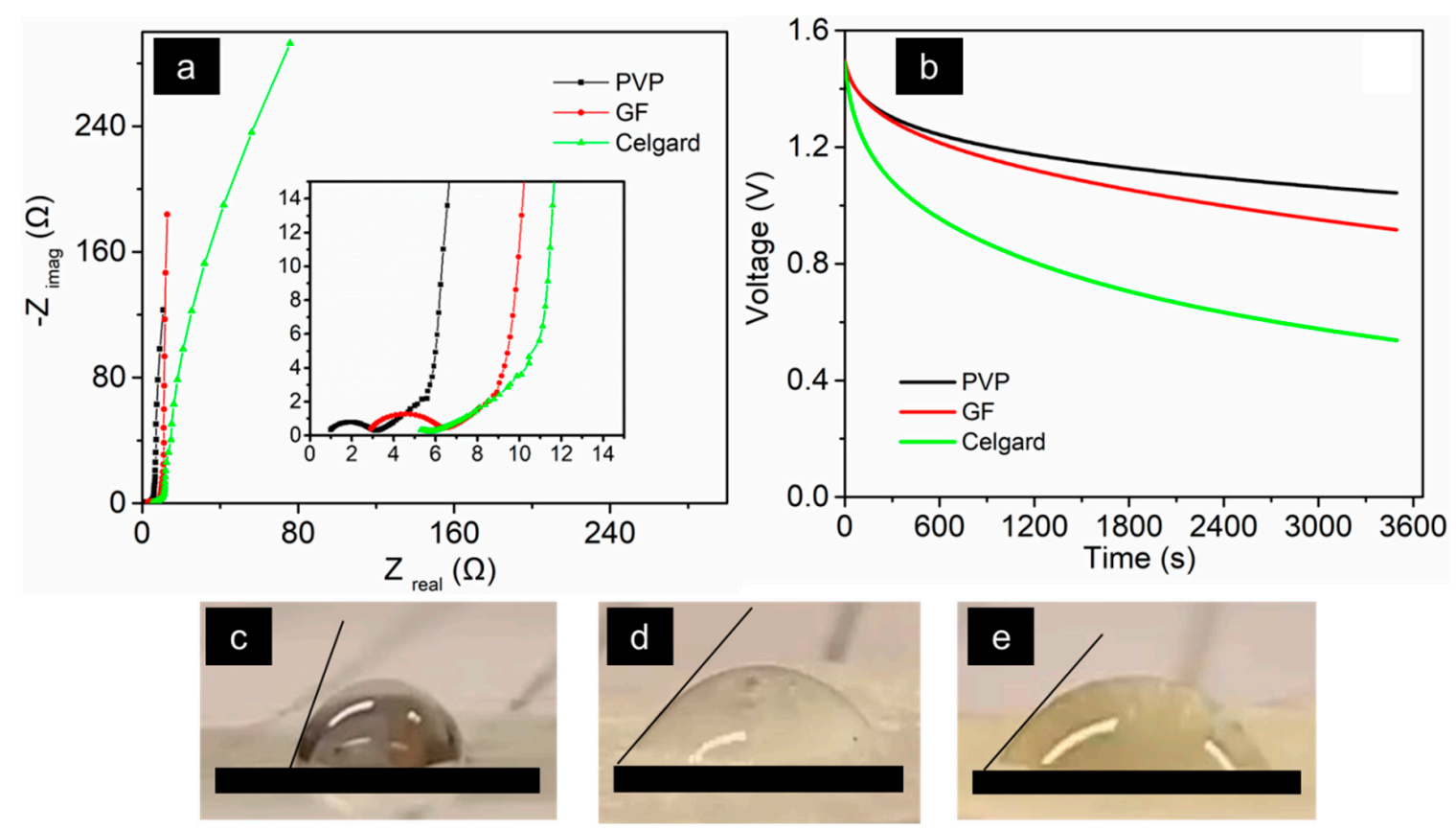

Figure 8. (a) Nyquist plot of the MSCs (same devices as in Figure 7). (b) Open circuit voltage (OCV) decay over time. The measurements used an AC electrode, 1-ethyl-3-methylimidazolium acetate (EmImAc) ionic liquid electrolyte, and three different separators. (c-e) The optical images used for the preliminary contact angle measurements of PVP, Glass fiber, and the Celgard separators, respectively.

Based on the above measurement results, electrospun PVP membranes could be considered as a promising separator material for MSCs. This is significant as electrospinning is a potentially attractive deposition method for the realization of MSCs based on stacked devices configurations. However, further material characterizations are required to fully understand the improved capacitive performance, compared to the commercial separators-as well as the development of more comprehensive device manufacturing schemes.

\subsection{Electrode/Current Collector Contact Resistance}

Contact resistance is a critically important feature in any microscale device $[73,74]$. For MSCs, the contact resistance between the electrode and current collector is important because it will contribute to energy losses during charging and discharging. This will affect the actual energy density of the device as well as the power density. In order to characterize and engineer a good electrical contact between carbon-based electrode materials and the current collector, we have fabricated transmission line model (TLM) characterization devices to evaluate the contact resistance between gold contacts and chemical vapor deposited (CVD) graphene, VG and rGO, respectively. 
A TLM device consists of multiple gold electrodes of various spacing that are placed on an insulating substrate (inset of Figure 9a). A patch of graphene covers the electrodes and forms an electrical connection between the electrodes. The electrical resistance between two neighboring electrodes is composed of the resistance of the intermediate graphene patch and the contact resistance between graphene and gold in both contact areas. To extract the contact resistance, the measured resistance between two neighboring electrodes is plotted against the respective electrode spacing. The contact resistance is derived by extrapolating the residual resistance at zero contact-spacing. In addition, multiplication of the width of the graphene patch with the slope of the linear fit yields the sheet resistance of the intermediate graphene patch. As an example, Figure 9a shows the extraction of contact resistance $\left(R_{c}\right)$ and sheet resistance $\left(R_{s}\right)$ of CVD graphene patches on gold contacts for three different TLM devices. Here, $R_{c}$ averages to $32.4 \pm 18.4 \Omega$ per contact and $R_{s}$ to $32.4 \pm 18.4 \Omega$ per contact and $R_{s}$ to $556.2 \pm 7.6 \Omega /$ square.

Another important feature is the influence of moisture as well as the presence of the electrolytes on the contact resistance of the device. Moisture has been shown to have a strong influence on electrolyte behavior [75] but there are no studies, to our knowledge, that specifically address the influence of moisture on the contact resistance in MSC devices. Only one study examined the influence of moisture on contact resistance in graphene devices [76]. As such, this work continues the progress already made in examining contact resistances between the electrode material and the gold current collectors, and provides a preliminary investigation of the influence of low levels of moisture on the contact resistance.

The same TLM devices with CVD graphene patches as in the inset of Figure 9awere measured at various humidity levels. The relative changes in $R_{c}$ and $R_{s}$ were plotted against the relative humidity (RH) (Figure $9 b$ ). The sheet resistance showed a significant increase of $0.6 \%$ when decreasing the $\mathrm{RH}$ from $20 \% R H$ to $10 \% R H$ whereas the contact resistance remained unaffected at these moisture levels. Note, both figures were extracted simultaneously from the very same measurement cycle. There is much room for future investigation (higher moisture concentration, in situ measurements of contact resistance in various electrolytes). However, this work aimed to provide some initial indication of graphene's insensitivity to moisture and establish a foundation for future investigations to build upon.
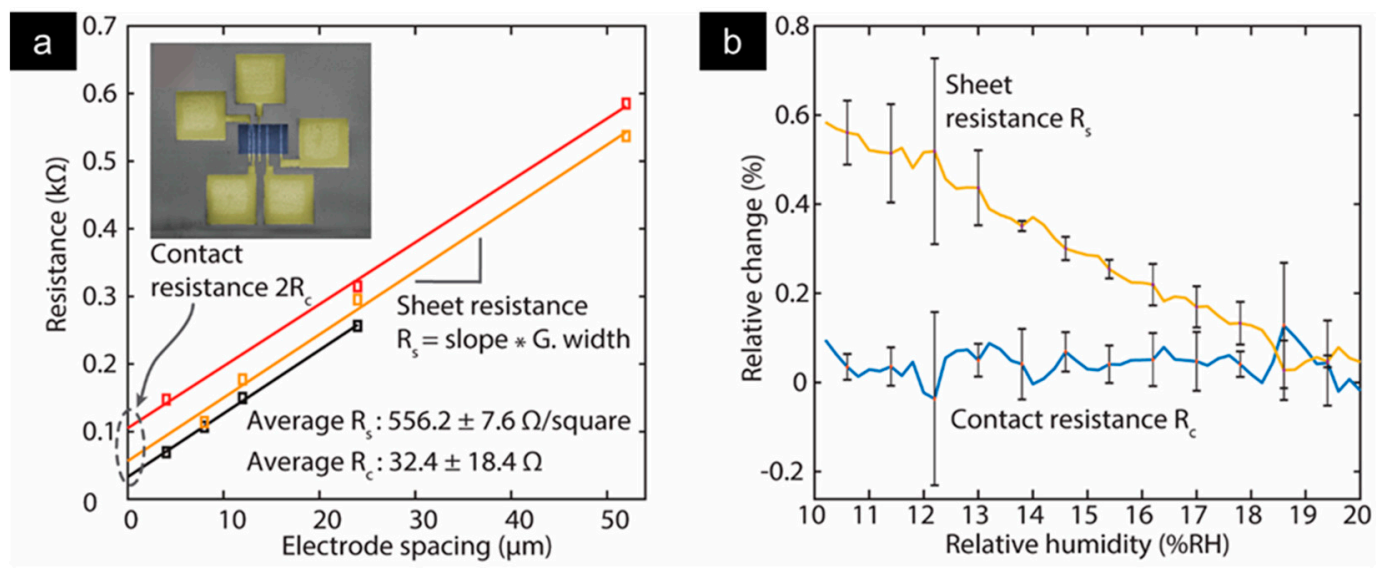

Figure 9. (a) Extraction of contact resistance of three transmission line model (TLM) devices with chemical vapor deposited (CVD) graphene patches on gold contacts. Extrapolating the linear fit (solid lines) of the measured resistance between the neighboring electrodes yields the contact resistance at the graphene/metal interface. Multiplication of the slope of the fit by the graphene patch results in the graphene sheet resistance. The inset displays a colorized scanning electron microscopy (SEM) photograph of a TLM device with gold contacts (yellow) and covering a graphene patch (blue). (b) Relative change in contact resistance and sheet resistance for variation in relative humidity (RH). Solid lines are the average of the three devices with $1 \sigma$ error bars. 


\section{Discussion}

As previously mentioned, the primary application for MSCs is in on-chip energy storage components integrated alongside micro-energy harvesters [17-20]. For the overall device integration, the MSC would likely be built on top of a traditional CMOS stack containing digital logic, including power management circuitry and rectifiers. Energy harvesters and sensors could be fabricated in a back end of the line (BEOL) process and connected to power the CMOS stack through metal vias. In one possible integration scheme, MSCs could be integrated on-chip with other application specific integrated circuit (ASIC) components using a wafer bonding process-forming a self-powering microsystem (schematic of potential future integration scheme displayed in Figure 10). Such a design has, to our knowledge, not been integrated into a single on-chip microsystem.

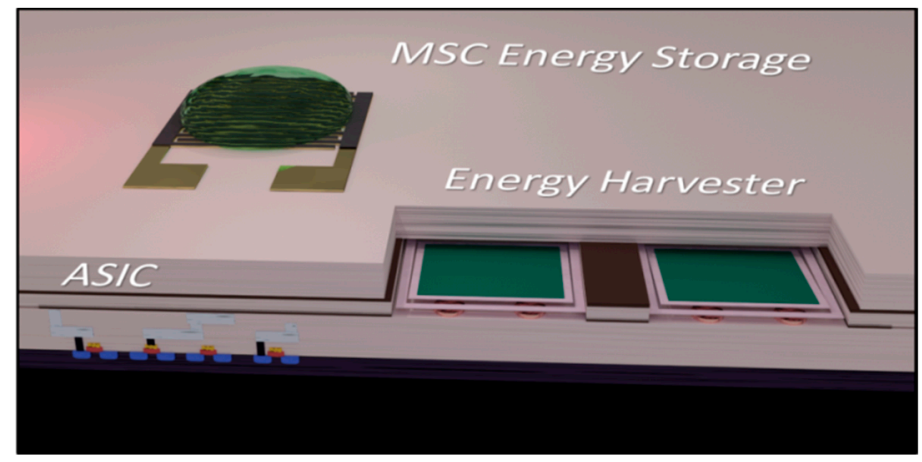

Figure 10. Schematic of a potential future self-powering system consisting back end of the line (BEOL) integration of an microsupercapacitors (MSC) and harvester with application specific integrated circuit (ASIC) components.

\section{Conclusions}

We presented a number of design investigations and improvements for the realization of high-performance MSCs that can be integrated with CMOS-based integrated circuits. The proposed MSCs feature carbon-based electrode materials and can be integrated at the back end of the line of the integrated circuit fabrication to realize microsystems for future self-powering devices. Several critical design features are highlighted that influence both performance and integration potential. These include careful design of current collector and electrode interfaces to improve energy density, minimize contact resistance, and improve adhesion and uniformity. We further propose a CMOS-compatible manufacturing and integration scheme for realizing a fully on-chip, self-powering microsystem that can benefit from the aforementioned improvements.

Author Contributions: Conceptualization, A.D.S.; Data curation, A.D.S., Q.L., A.V. (Agin Vyas), M.M.H., K.W., A.V. (Andres Velasco), X.Z., S.T. and A.Q.; Formal analysis, A.D.S., Q.L., A.V. (Agin Vyas), M.M.H., K.W., A.V. (Andres Velasco), X.Z., S.T. and A.Q.; Funding acquisition, A.D.S., X.Z., F.N., K.G. and P.E.; Investigation, A.D.S., Q.L., A.V. (Agin Vyas), M.M.H., K.W., A.V. (Andres Velasco), X.Z., S.T. and A.Q.; Methodology, A.D.S.; Project administration, A.D.S., X.Z., F.N., K.G., P.L. and P.E.; Resources, A.D.S., X.Z., F.N., K.G. and P.E.; Software, K.W.; Supervision, A.D.S., X.Z., F.N., K.G., P.L. and P.E.; Validation, A.D.S., Q.L., A.V. (Agin Vyas), M.M.H., K.W., A.V. (Andres Velasco), X.Z., S.T. and A.Q.; Visualization, A.D.S., Q.L., A.V. (Agin Vyas), M.M.H., K.W., A.V. (Andres Velasco), X.Z., S.T. and A.Q.; Writing - original draft, A.D.S., Q.L., A.V. (Agin Vyas), M.M.H., K.W., A.V. (Andres Velasco), X.Z., S.T. and A.Q.; Writing - review \& editing, A.D.S., Q.L., A.V. (Agin Vyas), M.M.H., K.W., A.V. (Andres Velasco), X.Z., S.T., A.Q., F.N., K.G., P.L. and P.E.

Funding: This research was funded by Area of Advance-Project MESSIAH: Microelectronic Energy Storage Systems Integrated Alongside Harvesters, Vinnova UDI-2: Miniaturized self-powered industrial sensor systems using energy harvesting technologies (2017-03725), Vinnova project NFFP7: Architecture for high-power radars (2017-04869), Chalmers Foundation, and Helge Ax:son Johnsons stiftelse (F19-0050).

Conflicts of Interest: The authors declare no conflict of interest. 


\section{References}

1. Mack, C.A. Fifty years of Moore's law. IEEE Trans. Semicond. Manuf. 2011, 24, 202-207. [CrossRef]

2. Waldrop, M.M. The chips are down for Moore's law. Nat. News 2016, 530, 144. [CrossRef] [PubMed]

3. Dreslinski, R.G.; Wieckowski, M.; Blaauw, D.; Sylvester, D.; Mudge, T. Near-threshold computing: Reclaiming moore's law through energy efficient integrated circuits. Proc. IEEE 2010, 98, 253-266. [CrossRef]

4. Schaller, R.R. Moore's law: past, present and future. IEEE Spectr. 1997, 34, 52-59. [CrossRef]

5. Yeric, G. Moore's law at 50: Are we planning for retirement? In Proceedings of the IEEE International Electron Devices Meeting (IEDM), Washington, DC, USA, 7-9 December 2015; p. 1.

6. Smith, A. Graphene-based devices for more than Moore applications. Ph.D. Thesis, KTH Royal Institute of Technology, Stockholm, Sweden, 2016.

7. Bataillou, J.; Coster, D.J.; Peterson, C.R.; Raff, J.; Stringer, C.J. Battery for a portable display device. U.S. Patent 29/473,939, 2014.

8. Sato, J.; Suzuki, S. Battery for portable computer. U.S. Patent 29/445,041, 2013.

9. Lin, P. Rechargeable battery device. U.S. Patent 29/502,986, 2016.

10. Goodenough, J.B.; Park, K.S. The Li-ion rechargeable battery: A perspective. J. Am. Chem. Soc. 2013, 135, 1167-1176. [CrossRef] [PubMed]

11. Gallo, A.B.; Simões-Moreira, J.R.; Costa, H.K.M.; Santos, M.M.; dos Santos, E.M. Energy storage in the energy transition context: A technology review. Renew. Sustain. Energy Rev. 2016, 65, 800-822. [CrossRef]

12. Dubal, D.P.; Chodankar, N.R.; Kim, D.H.; Gomez-Romero, P. Towards flexible solid-state supercapacitors for smart and wearable electronics. Chem. Soc. Rev. 2018, 47, 2065-2129.

13. Lu, X.; Yu, M.; Wang, G.; Tong, Y.; Li, Y. Flexible solid-state supercapacitors: design, fabrication and applications. Energy Environ. Sci. 2014, 7, 2160-2181. [CrossRef]

14. Dong, L.; Xu, C.; Li, Y.; Huang, Z.H.; Kang, F.; Yang, Q.H.; Zhao, X. Flexible electrodes and supercapacitors for wearable energy storage: A review by category. J. Mater. Chem. A 2016, 4, 4659-4685. [CrossRef]

15. Fu, Y.; Cai, X.; Wu, H.; Lv, Z.; Hou, S.; Peng, M.; Yu, X.; Zou, D. Fiber supercapacitors utilizing pen ink for flexible/wearable energy storage. Adv. Mater. 2012, 24, 5713-5718. [CrossRef]

16. Meng, Y.; Zhao, Y.; Hu, C.; Cheng, H.; Hu, Y.; Zhang, Z.; Shi, G.Q.; Qu, L. All-graphene core-sheath microfibers for all-solid-state, stretchable fibriform supercapacitors and wearable electronic textiles. Adv. Mater. 2013, 25, 2326-2331. [CrossRef] [PubMed]

17. Shen, C.; Xu, S.; Xie, Y.; Sanghadasa, M.; Wang, X.; Lin, L. A review of on-chip micro supercapacitors for integrated self-powering systems. J. Microelectromech. Syst. 2017, 26, 949-965. [CrossRef]

18. Roundy, S.; Wright, P.K.; Rabaey, J.M. Energy Scavenging for Wireless Sensor Networks; Springer: Berlin/ Heidelberg, Germany, 2003; pp. 45-47.

19. Paradiso, J.A.; Starner, T. Energy scavenging for mobile and wireless electronics. IEEE Pervasive Comput. 2005, 4, 18-27. [CrossRef]

20. Wang, Z.L. Towards self-powered nanosystems: From nanogenerators to nanopiezotronics. Adv. Funct. Mater. 2008, 18, 3553-3567. [CrossRef]

21. Schmuch, R.; Wagner, R.; Hörpel, G.; Placke, T.; Winter, M. Performance and cost of materials for lithium-based rechargeable automotive batteries. Nat. Energy 2018, 3, 267. [CrossRef]

22. Wang, Y.; Song, Y.; Xia, Y. Electrochemical capacitors: Mechanism, materials, systems, characterization and applications. Chem. Soc. Rev. 2016, 45, 5925-5950. [CrossRef] [PubMed]

23. Li, B.; Dai, F.; Xiao, Q.; Yang, L.; Shen, J.; Zhang, C.; Cai, M. Nitrogen-doped activated carbon for a high energy hybrid supercapacitor. Energy Environ. Sci. 2016, 9, 102-106. [CrossRef]

24. Liu, C.; Zhang, C.; Song, H.; Zhang, C.; Liu, Y.; Nan, X.; Cao, G. Mesocrystal MnO cubes as anode for Li-ion capacitors. Nano Energy 2016, 22, 290-300. [CrossRef]

25. Ding, J.; Hu, W.; Paek, E.; Mitlin, D. Review of hybrid ion capacitors: From aqueous to lithium to sodium. Chem. Rev. 2018, 118, 6457-6498. [CrossRef]

26. Du Pasquier, A.; Plitz, I.; Gural, J.; Badway, F.; Amatucci, G.G. Power-ion battery: Bridging the gap between Li-ion and supercapacitor chemistries. J. Power Sources 2004, 136, 160-170. [CrossRef]

27. Cericola, D.; Kötz, R. Hybridization of rechargeable batteries and electrochemical capacitors: Principles and limits. Electrochim. Acta 2012, 72, 1-17. [CrossRef] 
28. Dubal, D.P.; Ayyad, O.; Ruiz, V.; Gomez-Romero, P. Hybrid energy storage: The merging of battery and supercapacitor chemistries. Chem. Soc. Rev. 2015, 44, 1777-1790. [CrossRef] [PubMed]

29. Zuo, W.; Li, R.; Zhou, C.; Li, Y.; Xia, J.; Liu, J. Battery-supercapacitor hybrid devices: Recent progress and future prospects. Adv. Sci. 2017, 4, 1600539. [CrossRef]

30. Raza, W.; Ali, F.; Raza, N.; Luo, Y.; Kim, K.H.; Yang, J.; Kumar, S.; Mehmood, A.; Kwon, E.E.; Kumar, S.; et al. Recent advancements in supercapacitor technology. Nano Energy 2018, 52, 441-473. [CrossRef]

31. Zhong, C.; Deng, Y.; Hu, W.; Qiao, J.; Zhang, L.; Zhang, J. A review of electrolyte materials and compositions for electrochemical supercapacitors. Chem. Soc. Rev. 2015, 44, 7484-7539. [CrossRef] [PubMed]

32. Wang, G.; Zhang, L.; Zhang, J. A review of electrode materials for electrochemical supercapacitors. Chem. Soc. Rev. 2012, 41, 797-828. [CrossRef]

33. Zhi, M.; Xiang, C.; Li, J.; Li, M.; Wu, N. Nanostructured carbon-metal oxide composite electrodes for supercapacitors: A review. Nanoscale 2013, 5, 72-88. [CrossRef] [PubMed]

34. González, A.; Goikolea, E.; Barrena, J.A.; Mysyk, R. Review on supercapacitors: Technologies and materials. Renew. Sustain. Energy Rev. 2016, 58, 1189-1206. [CrossRef]

35. Wang, F.; Wu, X.; Yuan, X.; Liu, Z.; Zhang, Y.; Fu, L.; Zhu, Y.; Zhou, Q.; Wu, Y.; Huang, W. Latest advances in supercapacitors: From new electrode materials to novel device designs. Chem. Soc. Rev. 2017, 46, 6816-6854. [CrossRef] [PubMed]

36. Borenstein, A.; Hanna, O.; Attias, R.; Luski, S.; Brousse, T.; Aurbach, D. Carbon-based composite materials for supercapacitor electrodes: A review. J. Mater. Chem. A 2017, 5, 12653-12672. [CrossRef]

37. Wang, Q.; Yan, J.; Fan, Z. Carbon materials for high volumetric performance supercapacitors: Design, progress, challenges and opportunities. Energy Environ. Sci. 2016, 9, 729-762. [CrossRef]

38. Yan, J.; Wang, Q.; Wei, T.; Fan, Z. Recent advances in design and fabrication of electrochemical supercapacitors with high energy densities. Adv. Energy Mater. 2014, 4, 1300816. [CrossRef]

39. Deng, Y.; Xie, Y.; Zou, K.; Ji, X. Review on recent advances in nitrogen-doped carbons: Preparations and applications in supercapacitors. J. Mater. Chem. A 2016, 4, 1144-1173. [CrossRef]

40. Kumar, K.S.; Choudhary, N.; Jung, Y.; Thomas, J. Recent advances in two-dimensional nanomaterials for supercapacitor electrode applications. ACS Energy Lett. 2018, 3, 482-495. [CrossRef]

41. Pomerantseva, E.; Gogotsi, Y. Two-dimensional heterostructures for energy storage. Nat. Energy 2017, 2, 17089. [CrossRef]

42. He, Y.; Chen, W.; Li, X.; Zhang, Z.; Fu, J.; Zhao, C.; Xie, E. Freestanding three-dimensional graphene/MnO2 composite networks as ultralight and flexible supercapacitor electrodes. ACS Nano 2012, 7, 174-182. [CrossRef] [PubMed]

43. Smith, A.D.; Li, Q.; Anderson, A.; Vyas, A.; Kuzmenko, V.; Haque, M.; Staaf, L.G.H.; Lundgren, P.; Enoksson, P. Toward CMOS compatible wafer-scale fabrication of carbon-based microsupercapacitors for IoT. J. Phys. Conf. Ser. 2018, 1052, 012143. [CrossRef]

44. Li, Q.; Sun, S.; Smith, A.D.; Lundgren, P.; Fu, Y.; Su, P.; Xu, T.; YE, 1.; Sun, L.; Liu, J.; et al. Compact and low loss electrochemical capacitors using a graphite/carbon nanotube hybrid material for miniaturized systems. J. Power Sources 2019, 412, 374-383. [CrossRef]

45. Vyas, A.; Li, Q.; Cornaglia, F.; Wang, K.; Anderson, A.; Haque, M.; Kuzmenko, V.; Smith, A.D.; Lundgren, P.; Enoksson, P. Surface Roughening with Iron Nanoparticles for Promoted Adhesion of Spin Coated Microsupercapacitor Electrodes. MRS Adv. 2019, 4, 1335-1340. [CrossRef]

46. Ma, Y.; Chang, H.; Zhang, M.; Chen, Y. Graphene-based materials for lithium-ion hybrid supercapacitors. Adv. Mater. 2015, 27, 5296-5308. [CrossRef] [PubMed]

47. Shao, Y.; El-Kady, M.F.; Wang, L.J.; Zhang, Q.; Li, Y.; Wang, H.; Mousavi, M.F.; Kaner, R.B. Graphene-based materials for flexible supercapacitors. Chem. Soc. Rev. 2015, 44, 3639-3665. [CrossRef] [PubMed]

48. Li, Q.; Smith, A.D.; Haque, M.; Vyas, A.; Kuzmenko, V.; Lundgren, P.; Enoksson, P. Graphite paper/carbon nanotube composite: A potential supercapacitor electrode for powering microsystem technology. J. Phys. Conf. Ser. 2017, 922, 012014. [CrossRef]

49. Delekta, S.S.; Smith, A.D.; Li, J.; Östling, M. Inkjet Printing of Graphene for Sensing and Energy Storage Applications. Meeting Abstracts 2017, 12, 771.

50. Delekta, S.S.; Smith, A.D.; Li, J.; Östling, M. Inkjet printed highly transparent and flexible graphene micro-supercapacitors. Nanoscale 2017, 9, 6998-7005. [CrossRef] [PubMed] 
51. Pan, H.; Wang, D.; Peng, Q.; Ma, J.; Meng, X.; Zhang, Y.; Ma, Y.; Zhu, S.; Zhang, D. High-Performance Microsupercapacitors Based on Bioinspired Graphene Microfibers. ACS Appl. Mater. Interfaces 2018, 10, 10157-10164. [CrossRef]

52. Li, X.; Cai, W.; Teh, K.S.; Qi, M.; Zang, X.; Ding, X.; Cui, Y.; Xie, Y.; Wu, Y.; Ma, H.; et al. High-voltage flexible microsupercapacitors based on laser-induced grapheme. ACS Appl. Mater. Interfaces 2018, 10, 26357-26364. [CrossRef]

53. Beidaghi, M.; Wang, Z.; Gu, L.; Wang, C. Electrostatic spray deposition of graphene nanoplatelets for high-power thin-film supercapacitor electrodes. J. Solid State Electrochem. 2012, 16, 3341-3348. [CrossRef]

54. Kim, J.H.; Nam, K.W.; Ma, S.B.; Kim, K.B. Fabrication and electrochemical properties of carbon nanotube film electrodes. Carbon 2006, 44, 1963-1968. [CrossRef]

55. Du, C.; Pan, N. High power density supercapacitor electrodes of carbon nanotube films by electrophoretic deposition. Nanotechnology 2006, 17, 5314. [CrossRef]

56. Du, C.; Pan, N. Supercapacitors using carbon nanotubes films by electrophoretic deposition. J. Power Sources 2006, 160, 1487-1494. [CrossRef]

57. Kim, C.; Kang, D.Y.; Moon, J.H. Full lithographic fabrication of boron-doped 3D porous carbon patterns for high volumetric energy density microsupercapacitors. Nano Energy 2018, 53, 182-188. [CrossRef]

58. Kumar, R.; Savu, R.; Joanni, E.; Vaz, A.R.; Canesqui, M.A.; Singh, R.K.; Timm, R.A.; Kubota, L.T.; Moshkalev, S.A. Fabrication of interdigitated micro-supercapacitor devices by direct laser writing onto ultra-thin, flexible and free-standing graphite oxide films. RSC Adv. 2016, 6, 84769-84776. [CrossRef]

59. Zhang, W.; Lei, Y.; Ming, F.; Jiang, Q.; Costa, P.M.; Alshareef, H.N. Lignin Laser Lithography: A Direct-Write Method for Fabricating 3D Graphene Electrodes for Microsupercapacitors. Adv. Energy Mater. 2018, 8, 1801840. [CrossRef]

60. Thakur, S.; Karak, N. Green reduction of graphene oxide by aqueous phytoextracts. Carbon 2012, 50, 5331-5339. [CrossRef]

61. Dresselhaus, M.S.; Jorio, A.; Hofmann, M.; Dresselhaus, G.; Saito, R. Perspectives on carbon nanotubes and graphene Raman spectroscopy. Nano Lett. 2010, 10, 751-758. [CrossRef] [PubMed]

62. Anoshkin, I.V.; Nefedova, I.I.; Lioubtchenko, D.V.; Nefedov, I.S.; Räisänen, A.V. Single walled carbon nanotube quantification method employing the Raman signal intensity. Carbon 2017, 116, 547-552. [CrossRef]

63. Xu, C.; Shi, L.; Ji, A.; Shi, X.; Wang, X.; Wang, X. Synthesis and characterization of reduced graphene oxide with D-fructose and D-galactose as reductants. J. Nanosci. Nanotechnol. 2016, 16, 9914-9918. [CrossRef]

64. Ferrari, A.C.; Meyer, J.C.; Scardaci, V.; Casiraghi, C.; Lazzeri, M.; Mauri, F.; Piscanec, S.; Jiang, D.; Novoselov, K.S.; Roth, S.; et al. Raman spectrum of graphene and graphene layers. Phys. Rev. Lett. 2006, 97, 187401. [CrossRef]

65. Fang, J.; Levchenko, I.; Kumar, S.; Seo, D.; Ostrikov, K.K. Vertically-aligned graphene flakes on nanoporous templates: Morphology, thickness, and defect level control by pre-treatment. Sci. Technol. Adv. Mater. 2014, 15, 055009. [CrossRef] [PubMed]

66. McAllister, M.J.; Li, J.L.; Adamson, D.H.; Schniepp, H.C.; Abdala, A.A.; Liu, J.; Herrera-Alonso, M.; Milius, D.L.; Car, B.; Prud'homme, R.K.; et al. Single sheet functionalized graphene by oxidation and thermal expansion of graphite. Chem. Mater. 2007, 19, 4396-4404. [CrossRef]

67. Kuzmenko, V.; Naboka, O.; Haque, M.; Staaf, H.; Göransson, G.; Gatenholm, P.; Enoksson, P. Sustainable carbon nanofibers/nanotubes composites from cellulose as electrodes for supercapacitors. Energy 2015, 90, 1490-1496. [CrossRef]

68. Li, J.C.; Hou, P.X.; Liu, C. Heteroatom-Doped Carbon Nanotube and Graphene-Based Electrocatalysts for Oxygen Reduction Reaction. Small 2017, 13, 1702002. [CrossRef] [PubMed]

69. Kumar, N.A.; Baek, J.B. Doped graphene supercapacitors. Nanotechnology 2015, 26, 492001. [CrossRef] [PubMed]

70. Davies, A.; Yu, A. Material advancements in supercapacitors: From activated carbon to carbon nanotube and grapheme. Can. J. Chem. Eng. 2011, 89, 1342-1357. [CrossRef]

71. Zhang, S.S. A review on the separators of liquid electrolyte Li-ion batteries. J. Power Sources 2007, 164, 351-364. [CrossRef]

72. Haque, M.; Li, Q.; Smith, A.D.; Kuzmenko, V.; Köhler, E.; Lundgren, P.; Enoksson, P. Thermal influence on the electrochemical behavior of a supercapacitor containing an ionic liquid electrolyte. Electrochim. Acta 2018, 263, 249-260. [CrossRef] 
73. Schwierz, F. Graphene Transistors: Status, Prospects, and Problems. Proc. IEEE 2013, 101, 1567-1584. [CrossRef]

74. Venugopal, A.; Colombo, L.; Vogel, E.M. Contact resistance in few and multilayer graphene devices. Appl. Phys. Lett. 2010, 96, 013512. [CrossRef]

75. Azaïs, P.; Duclaux, L.; Florian, P.; Massiot, D.; Lillo-Rodenas, M.A.; Linares-Solano, A.; Peres, J.P.; Jehoulet, C.; Béguin, F. Causes of supercapacitors ageing in organic electrolyte. J. Power Sources 2007, 171, 1046-1053. [CrossRef]

76. Quellmalz, A.; Smith, A.D.; Elgammal, K.; Fan, X.; Delin, A.; Östling, M.; Lemme, M.; Gylfason, K.B.; Niklaus, F. Influence of Humidity on Contact Resistance in Graphene Devices. ACS Appl. Mater. Interfaces 2018, 10, 41738-41746. [CrossRef] [PubMed]

(C) 2019 by the authors. Licensee MDPI, Basel, Switzerland. This article is an open access article distributed under the terms and conditions of the Creative Commons Attribution (CC BY) license (http://creativecommons.org/licenses/by/4.0/). 